
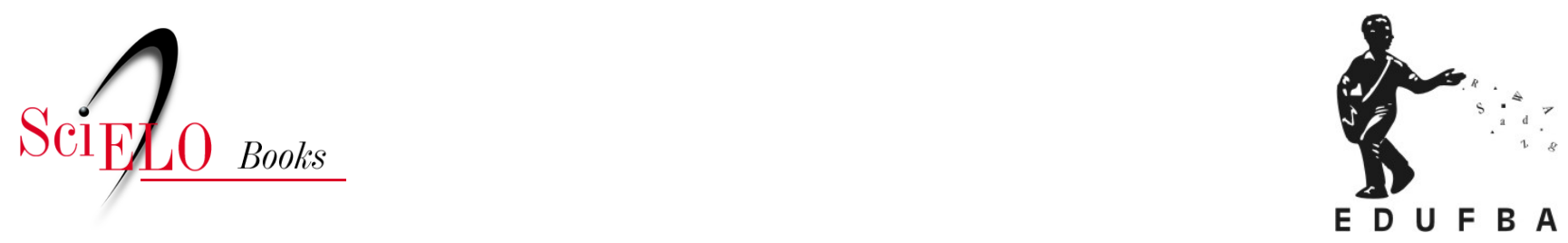

\title{
Florete flores \\ a poética da Sagrada Escritura no Seminário de Belém de Cachoeira
}

\author{
Belinda Maria de Almeida Neves
}

\section{SciELO Books / SciELO Livros / SciELO Libros}

NEVES, B.M.A. Florete flores: a poética da Sagrada Escritura no Seminário de Belém de Cachoeira. In: HERNÁNDEZ, M.H.O., and LINS, E.Á., eds. Iconografia: pesquisa e aplicação em estudos de Artes Visuais, Arquitetura e Design [online]. Salvador: EDUFBA, 2016, pp. 70-91. ISBN: 978-85232-1861-4. https://doi.org/10.7476/9788523218614.0005.

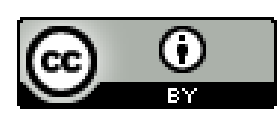

All the contents of this work, except where otherwise noted, is licensed under a Creative Commons Attribution 4.0 International license.

Todo o conteúdo deste trabalho, exceto quando houver ressalva, é publicado sob a licença $\underline{\text { Creative Commons }}$ Atribição 4.0. 
Florete Flores:

a poética da

Sagrada Escritura no

Seminário de Belém.

de Cachoeira

Belinda Maria de Almeida Neves 


\section{Introdução}

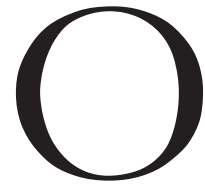

Seminário de Nossa Senhora de Belém foi uma instituição de ensino de grande importância para a formação e erudição colonial nos séculos XVII e XVIII. Popularmente chamado de Seminário de Belém de Cachoeira, foi fundado em 1686 pelo jesuíta Alexandre de Gusmão (1629-1724), às margens do Rio Paraguaçu, a uma légua distante do porto de Cachoeira, Recôncavo baiano.

Alexandre de Gusmão nasceu em Lisboa, em 14 de agosto de 1629. Chegou ao Brasil ainda criança, acompanhando seus pais, e ingressou na Companhia de Jesus na cidade do Rio de Janeiro, em 27 de outubro de 1646.

Foi considerado o maior pedagogo do período colonial e também um dos mais célebres da Companhia de Jesus. Exerceu, ao longo da vida religiosa, os cargos de Mestre de Noviços e Reitor Provincial. Destacou-se também como escritor, deixando um legado de 13 obras. ${ }^{1}$

1 Escola de Belém, Jesus nascido no Presepio (1678); História do predestinado peregrino e seu irmão Precito (1682); A arte de criar bem os filhos na idade puerícia (1685); Sermão na Catedral da Baía de Todos os Santos (1686); Meditação para todos os dias da semana (1689); Meditationes digestae per annum e Menino Cristão (1695); Rosa de Nazareth nas Montanhas de Hebron (1709); Eleição entre o bem \& mal eterno (1717); e as obras póstumas O corvo e a pomba da Arca de Noé e Arvore da Vida (1734); Compendium perfectionis religiosae (1783); e Preces recitandae statis temporibus ab Seminarii Bethemici (data imprecisa). 
Ao falecer, em 15 de março de 1724, foi sepultado no local que idealizou e construiu: a Igreja do Seminário de Belém. Tinha, então, 95 anos e 60 de sacerdócio.

O Seminário idealizado por Alexandre de Gusmão foi o primeiro internato para leigos e religiosos estabelecido na Colônia, oportunizando ensino de qualidade aos estudantes de todas as regiões do Brasil.

Conforme Afrânio Peixoto (1876-1947), no Livro de horas, "Gusmão tinha convicções arraigadas sobre a educação, não só para a vida religiosa, e não apenas para a Companhia, e até para a sociedade. Por fim, depois de Maria, ou a vocação, Maria, ou a ação". (PEIXOTO, 1947, p. 59-60)

A doutrina religiosa mesclava-se aos textos clássicos de Aristóteles, Ovídio, Horácio e tantos outros no programa pedagógico indicado pelo Ratio Studiorum, vigente desde 1599 e norteador do ensino em todos os Colégios da Companhia de Jesus nos quatro continentes. ${ }^{2}$ No referido programa, estudava-se gramática, humanidades e retórica, nos estudos inferiores. Nos superiores, teologia, filosofia e matemática.

Entretanto, do início das atividades do Seminário ao resplendor da fama, alguns anos foram necessários. "A fundação fora de 1686; levaria anos para edificar, abriu com oito alunos, mas já em 90 são 37; em 93, 50; em 96, 80; concluído o Colégio, em 1707, serão 114, e vai por aí". (PEIXOTO, 1947, p. 60)

O sucesso do Seminário ecoava pela Colônia e também pelo Velho Continente e, a cada ano, novos estudantes ingressavam na Instituição. Belém de Cachoeira era fruto da ação direta do Padre Alexandre de Gusmão. Estima-se que, até a expulsão dos jesuítas do Brasil em 1760, tenham ocupado suas dependências mais de mil alunos. Dali, boa parte dos nobres egressos seguiria para Coimbra na continuidade dos estudos. Outra parte seguiria a vocação religiosa.

Era inevitável a associação do Seminário ao jesuíta Gusmão, pela sua erudição, visão pedagógica e sistêmica. Godofredo Filho (1937, p. 102-103), em artigo publicado no primeiro exemplar da Revista do Patrimônio Histórico e Artístico Nacional, contempla o Seminário de Belém de Cachoeira e, por sua vez, o renomado jesuíta, tido, pelo autor, como "um dos mais ilustres varões da Companhia, notável não só pelas muitas letras, mas pelas egrégias virtudes que lhe alcançaram a nomeada de Venerável [...], perdurando até hoje a fama que o nivela aos Nóbrega e Anchieta".

Estimamos que o Padre Alexandre de Gusmão tivesse como desafio a solidificação do Seminário como um modelo de ensino a ser seguido. Aquela ins-

2 Conforme João Adolfo Hansen (2001, p. 17), o Ratio Studiorum foi aprovado pelo Geral da Companhia de Jesus, P. Claudio Acquaviva, em 8 de dezembro de 1598, e publicado em Nápoles, em janeiro de 1599, com o título de Ratio atque Institutio Studiorum Societatis Iesu. Daí em diante, passou a organizar o ensino de todos os colégios da Companhia até a dissolução da mesma no século XVIII. 
tituição visava boa formação cultural, social e religiosa de meninos para a maior glória de Deus (Ad maiorem Dei gloriam), o lema da Companhia de Jesus.

O Seminário de Nossa Senhora de Belém foi erigido bem próximo ao povoado de Cachoeira, no Recôncavo baiano. De povoado pequeno, criado em 1533, mas nem por isso menos importante, foi elevado à Freguesia de Nossa Senhora do Rosário em 1674, e, em 1698, tornou-se Vila de Nossa Senhora do Rosário do Porto de Cachoeira do Paraguaçu.

Ainda de acordo com Godofredo Filho (1937, p. 101), "o local, pela sugestão do silêncio e agreste solitude, não poderia ser melhor para que o escolhesse a pedagogia jesuítica". Seminário e Vila distanciavam-se cerca de $120 \mathrm{~km}$ da cidade da Bahia, capital da Província, onde ali estava o principal Colégio da Companhia de Jesus na Colônia.

\section{Os lavores artísticos}

Apesar da fama pedagógica adquirida, pouco se sabe sobre questões autorais na arquitetura e decoração da Igreja e do Seminário, as etapas de construção, os artistas que ali deixaram suas impressões e o programa iconográfico estabelecido. O Seminário de Nossa Senhora de Belém ainda representa uma lacuna para a história da arte brasileira. Conforme Godofredo Filho (1937, p. 105),

Dir-se-ia que, naqueles anos remotos do século XVII, a chamado do preclaro fundador, teriam ocorrido, aos campos de Belém, para decorar a capela do Seminário, os mais bizarros e famosos ensambladores e imaginários da Companhia. O certo é que, na solidão do planalto cachoeirano, se levantou um dia essa igreja suntuosa, florida internamente de figuras e linhas douradas, de obras no jacarandá, e até nos azulejos, nas lacas, dos marfins, das tartarugas e dos desenhos do Oriente.

Dos lavores artísticos de Belém de Cachoeira, pouco restou. Parte do que hoje conhecemos do contingente artístico do Seminário é oriundo do Inventário, ${ }^{3}$ realizado nas dependências daquela instituição, quando da expulsão dos jesuítas em 1760; e das obras que estão hoje expostas no Museu das Alfaias, em Cachoeira, e no Museu de Arte Sacra da Universidade Federal da Bahia (UFBA), em Salvador.

No referido Inventário, constam uma imagem de Nossa Senhora da Conceição, em retábulo ainda por pintar, três altares com incrustações de casco de

3 Conforme Godofredo Filho (1937), no volume XXXI dos Anais da Biblioteca Nacional (Documento 4.894), encontra-se o Instrumento do Inventário dos ornamentos, ouro, prata e mais alfaias pertencentes ao Seminário de Belém. Traz a data de janeiro $(22$ e 23) de 1760. Parte desse inventário encontra-se disponível em: < vapordecachoeira. blogspot.com.br/2009/10/pombal-expulsa-os-jesuitas-do-brasil-e.html>. Acesso em: 12 dez. 2013. 
tartaruga, e o teto da nave da Igreja, "cujo forro hé imitação de abóboda, pintada de varias cores e o altar de tartaruga e em partes fingidas com duas portas, com suas sanefas na forma sobredita, que tem sahida para a Sachristia e com suas grades de jacarandá, torneadas no arco". (GODOFREDO FILHO, 1937, p. 111) O Inventário refere-se ainda a "mais dois altares collateraes da mesma tartaruga, hum da parte do Evangelho da Senhora Santa Anna e o da parte da Epístola do Senhor São Joaquim". (GODOFREDO FILHO, 1937, p. 111) A ornamentação em tartaruga também está presente nos arremates dos púlpitos.

Serafim Leite (2008, p. 194, grifo do autor), em Artes e ofícios dos jesuitas no Brasil, afirma que Padre Alexandre de Gusmão "tinha habilidade manual de marceneiro e ensamblador: presépios de madeira e embutidos de tartaruga. Também se diz que pintou uma Natividade; mas desta qualidade de pintor não vimos fonte de primeira mão".

O envolvimento do Padre Alexandre de Gusmão com o programa iconográfico estabelecido no Seminário é evidente, mas, mediante as afirmações de Serafim Leite, é possível que o mesmo tenha participado ativamente da ornamentação daquele conjunto, juntamente com os Irmãos da Companhia.

Com a expulsão dos jesuítas, o Seminário foi extinto e, por longo tempo, esteve em total estado de abandono. De acordo com Godofredo Filho (1937), em 1817, o espaço foi cedido a Joaquim do Livramento e, ali, foi estabelecida uma Casa Pia de Educação para menores órfãos e desamparados. Posteriormente, em 1826, D. Pedro I expediu um Aviso, mandando fundar, naquele espaço, um Colégio Público.

Da expulsão dos jesuítas e elaboração do Inventário do Seminário até o artigo de Godofredo Filho, em 1937, muito daquele acervo se perdeu nesses 170 anos. "De suas faladas tartarugas embutidas, nada encontramos. Nem dos ornatos de marfim. Nem dos retábulos. Nem dos azulejos do Rato. Apenas, quase irreconhecíveis, algumas arcas de jacarandá e velhas imagens". (GODOFREDO FILHO, 1937, p. 105)

O autor afirma ainda que, após a expulsão, "prossegue a história das vicissitudes da casa, até o seu desaparecimento, pois, de Belém, restam apenas a igreja (quase arruinada) e dois arcos romanos do velho claustro". (GODOFREDO FILHO, 1937, p. 103)

Em 17 de junho de 1938, o que restou do conjunto do Seminário de Nossa Senhora de Belém foi tombado ${ }^{4}$ pelo Instituto do Patrimônio Histórico e Artístico Nacional (IPHAN). A descrição da Igreja, feita pelo referido órgão, pode ser conferida a seguir:

4 Processo de Tombamento 0122-T-38, disponível em: <www.iphan.gov.br>. Acesso em: 22 de nov. de 2013. 
A igreja com estrutura de paredes auto-portantes de alvenaria mista de pedra e tijolo. Sua planta consiste em nave única e sacristia transversal, flanqueada por corredores laterais, superpostos por galerias e tribunas avarandadas. Fachada dividida em 3 partes por pilastras, tendo em um dos lados, uma única torre, piramidal, revestida de azulejos e pedaços de louça oriental. A fachada atual, com frontão rococó e 4 janelas rasgadas do coro são do final do séc. XIX. O rico acervo de imagens e frontal do altar, em mármore com incrustações, pode ser visto no Museu das Alfaias, na Igreja Matriz de Nossa Senhora do Rosário, em Cachoeira. (IPHAN, [200-])

Pela descrição do IPHAN, a fachada anterior foi substituída por outra, em estilo rococó, no século XIX. Entretanto, o revestimento da torre, um embrechado de azulejos e louça oriental, sobreviveu até a atualidade e ainda pode ser conferido no local. "Nas horas de sol intenso e nas noites de grande luar, ela aparece, milionária de cintilações. São fragmentos de louça tapeando um fundo sobre que se cruzam, em linhas curiosas, pratos inteiros, que nada perderam o brilho e colorido primitivos". (GODOFREDO FILHO, 1937, p. 105)

O Brasil estava na rota da Europa para o Oriente, e também eram frequentes as comunicações entre os diversos colégios da Companhia de Jesus. Possivelmente, as louças e pratos inteiros que ornamentam aquela torre sejam provenientes de Macau.

Além da torre, outros lavores relevantes sobreviveram ao tempo. Um deles é o teto da sacristia, pintado em oito caixotões com motivos florais e orientais, atribuído ao jesuíta Carlos Belleville (1657-1730), que passou 10 anos na China e estabeleceu-se no Brasil em 1708.

Segundo Serafim Leite (2008, p. 129-130), em Artes e ofícios dos jesuitas no Brasil, "a pintura parece ter sido a principal ocupação do Ir. Belleville. [...] No catálogo de 1719, diz-se pintor e estatuário". Afirma ainda o autor que "presumível a pintura do tecto da Igreja de Belém de Cachoeira porque se trata de arte florida de caráter chinês". (LEITE, 2008, p. 130, grifo do autor)

Carlos Belleville, desde que chegou ao Brasil, possivelmente não se ausentou da Bahia. Serafim Leite atribui a ele outras presumíveis obras no Noviciado da Jequitaia, em Salvador. Carlos Ott (1993, p. 35), em História das artes plásticas da Babia (1550-1900), atribui a Belleville pinturas na antiga igreja do Colégio da Bahia e em outros espaços da Colônia. Entretanto, as referidas pinturas não se assemelham às impressões chinesas evidentes, como as que podem ser apreciadas naquele Seminário.

Outro exemplar relevante proveniente da Igreja do Seminário de Nossa Senhora de Belém é o frontal do altar, objeto principal de nossa pesquisa neste 
artigo. Trata-se de um trabalho em estuque, elaborado em cal esgrafiada, com motivos naturalistas e estilo brutesco. A obra encontra-se exposta no Museu de Arte Sacra da UFBA, em regime de comodato. Naquele museu, chegou em 22 de março de 1974, ${ }^{5}$ autorizada pelo Cardeal D. Avelar Brandão Vilela e Monsenhor Fernando Carneiro. Foi recebida, a título de empréstimo, por Valentin Calderón, então diretor da instituição. Apresentando algumas fissuras, passou por pequena intervenção de restauro, na gestão do atual diretor, Francisco Portugal.

O referido frontal de altar, até chegar ao Museu de Arte Sacra da UFBA, esteve exposto no Museu das Alfaias, nas dependências da Igreja Matriz de Nossa Senhora do Rosário, em Cachoeira. A ficha catalográfica do museu apresenta a seguinte descrição:

Rara peça de sóbrio colorido, cuja técnica e decoração têm sua origem na arte colonial indo-portuguesa. Uma grande cartela manuscrita no centro da composição e os acantos que se entrelaçam por todas as partes estabelecem a simbiose entre a estética Ocidental e a Oriental, manifesta no desenho de pássaros, borboletas e flores que deram profusamente este belo espécime mandado fazer pelo P. Alexandre de Gozman, SJ, para o altar mor da Igreja do Seminário de Belém, por ele fundado nos últimos anos do século XVII. No centro da cartela o lema do Seminário: Florete Flores. ${ }^{6}$

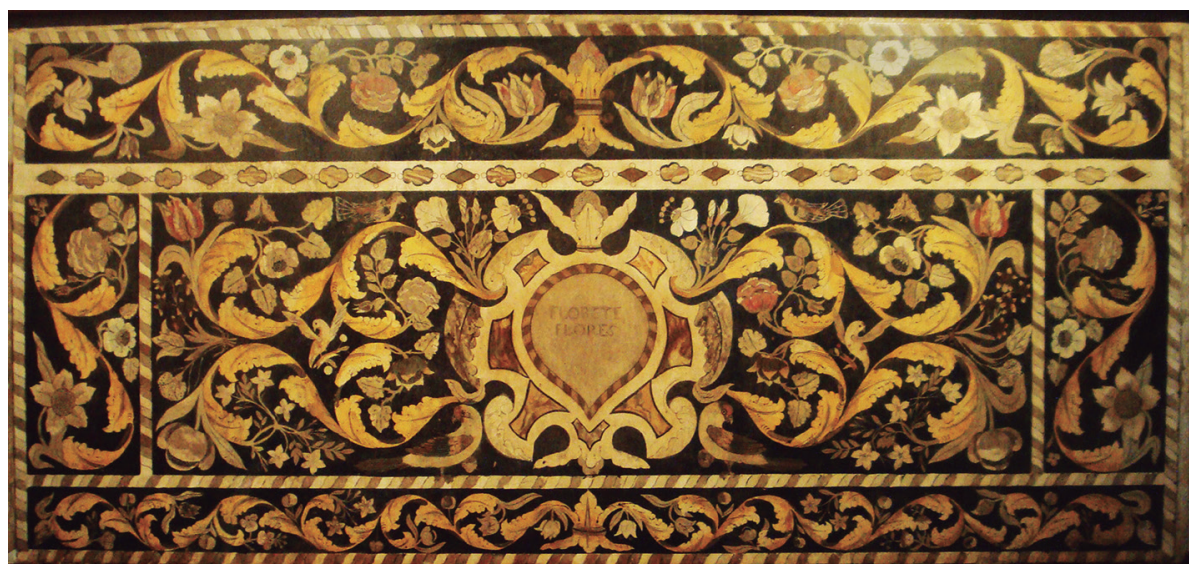

Figura 1 - Frontal do altar da Igreja do Seminário de Nossa Senhora de Belém, Cachoeira, Bahia. Estuque

Fonte: Neves (2013).

5 Catalogada como B.C 01 - Frontal de Altar

6 As informações citadas foram retiradas da ficha catalográfica do Frontal de Altar Igreja do Seminário de Nossa Senhora de Belém, exposto no Museu de Arte Sacra da UFBA em Salvador. 
Trata-se de uma peça relevante para a iconografia brasileira. Os lavores em estuque, de cal esgrafiada, também chamados esgrafitos, simulam embrechado em mármore multicolorido.

Embora a técnica do estuque seja antiga e a "pintura de fingidos" uma prática bem comum em Portugal e na Colônia, não é tão simples sua execução aos moldes do resultado apresentado naquela obra. Foi executado por artista experiente na técnica, elaborado com maestria. Motivos naturalistas semelhantes também ornamentaram os frontais dos altares confeccionados em tecido, bordados a fio de seda e ouro, a exemplo dos que podem ser apreciados no Museu de São Roque, em Lisboa.

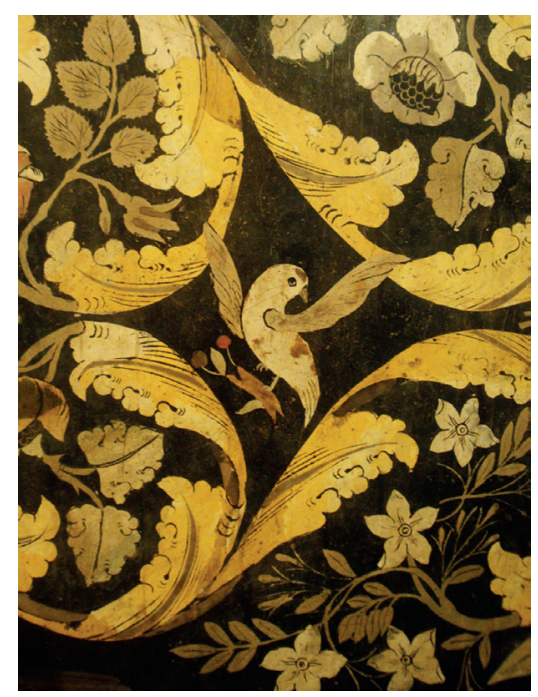

Figura 2 - Detalhe do frontal de altar do Seminário Fonte: Neves (2013).

As encomendas de altares em mármore, portugueses ou italianos, além de muito dispendiosas, eram demoradas. A solução encontrada no Seminário de Belém de Cachoeira, possivelmente, atendeu às expectativas estéticas dos religiosos e do público na ocasião e, na atualidade, a obra foi capaz de iludir olhares técnicos e experientes que se referiram ao frontal como mármore. Entretanto, a autoria e datação precisas desta obra são desconhecidas.

No Brasil Colonial, a técnica do estuque e a cal como matéria-prima proporcionaram a simulação de madeira e pedra nas mãos de muitos artistas. A antiga técnica, mais conhecida como "pintura de fingidos", foi amplamente utilizada para simular, em espaços religiosos, materiais superiores aos que se tinha, mas nem por isso obteve-se resultado insatisfatório no aspecto artístico. 
A dificuldade de recursos e a necessidade de execução de um programa iconográfico para os templos viabilizaram a sua utilização.

Para Ernst Gombrich (2012, p. 174), em O sentido de ordem: um estudo sobre a psicologia da arte decorativa, "os arquitetos modernos têm um termo para esse tipo de imitação: chamam-no de mimetismo" e esclarece que "o mimetismo era identificado ao desejo vulgar de não ficar atrás dos vizinhos, sendo condenado, portanto, em nome da honestidade". O autor complementa e interpreta a sua utilização como um aspecto positivo: "em vez disso, podemos vê-lo como um sucesso da imaginação, a descoberta da ficção, a libertação de uma literalidade em uma lúdica mudança de funções". Assim foi a elasticidade artística na Colônia e no Seminário de Belém de Cachoeira.

Guilherme Simões Gomes Junior (1998), em Palavra pelegrina: o barroco e o pensamento sobre artes e letras no Brasil, complementa esse pensamento quando informa que, aos jesuítas, coube uma adaptação aos materiais e às condições disponíveis. "E, se na Europa, os jesuítas reproduziram certa uniformidade o padrão arquitetônico de sua sede em Roma, em outros lugares, adaptaram-se a outros padrões conforme as condições e necessidades locais". (GOMES JUNIOR, 1998, p. 67)

O mesmo pode ser observado na atividade artística dos padrões decorativos, cujos muitos dos exemplares encontrados nos templos jesuíticos do Brasil podem ser considerados únicos ou singulares. Nesse rol, estão retábulos, pinturas, estuques, imaginária, que se diferenciam consideravelmente de um templo para outro.

Da mesma forma, o estilo brutesco esteve refletido na pintura e escultura dos séculos XVI até início do XVIII, com a predominância artística de flores, animais, folhagens, frutos da terra, indígenas, animais fantásticos e híbridos. Esse estilo foi comumente adotado em tetos e retábulos no Brasil, sendo primeiramente popular em Portugal e Espanha, posteriormente refletindo-se nas suas colônias.

As impressões naturalistas zoofitomorfas dos artistas na arte religiosa da colônia brasileira também podem ser entendidas como a apropriação da cultura local, no sentido de compreensão, absorção e domínio.

Vítor Serrão (2006), em Os programas imagéticos na arte barroca portuguesa e a sua repercussão nos espaços coloniais luso-brasileiros, aborda o brutesco e o Barroco, as noções da arte ultramarina e a contextualização dos artistas que produziram no Brasil Colônia. Para o autor, ainda faltam pesquisas que identifiquem o grande contingente de brutesco nos espaços coloniais e sugere a junção de pesquisadores brasileiros e portugueses para melhor análise deste contingente e da temática.

7 Ressaltamos as evoluções do conceito de mimesis, utilizado por Aristóteles e Platão na Antiguidade. 
O reconhecimento dos acervos patrimoniais brasileiros tem permitido revelar nos últimos anos, a par de muito conhecido conjunto de forros de pintura perspéctica, uma série de testemunhos de utilização tardia da linguagem decorativa de brutesco, que, a partir da metrópole, se iria espalhar por todo o espaço lusófono, de Angola a Macau, à Índia e, naturalmente, o Brasil. (SERRÃO, 2006, p. 1398)

A representação artística do brutesco nas colônias lusófonas, em parte de Portugal e do Brasil, foi amplamente reproduzida, transformada, adaptada mediante influências recebidas. No caso da Companhia de Jesus, o contato com Colégios de várias localidades e as viagens de sacerdotes possibilitaram, por muitas vezes, a presença de estilos variados em seus templos.

\section{0 simbolismo}

Embora de relevante valor estético e iconográfico, o frontal do altar a que nos referimos não deve ser interpretado apenas como ornamento. A iconologia nos permite visualizar que ali estão muitos elementos que dialogam, de forma poética, com a Sagrada Escritura e as aspirações pedagógicas e artísticas do Padre Alexandre de Gusmão para o Seminário de Nossa Senhora de Belém.

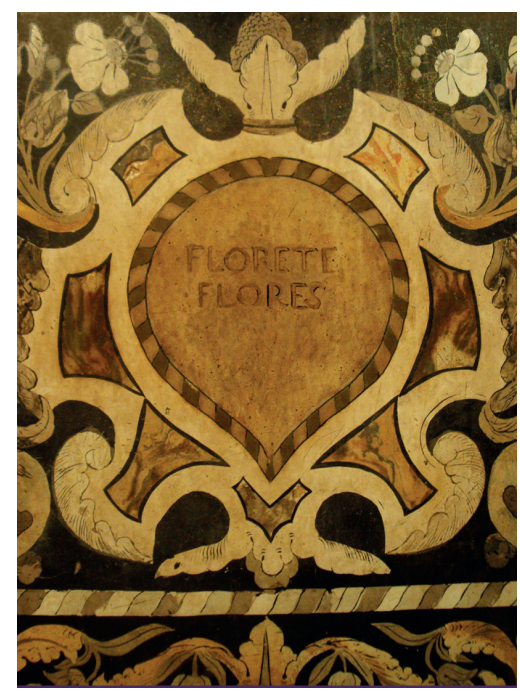

Figura 3 - Detalhe da cartela central do frontal do altar, com a inscrição Florete flores Fonte: Neves (2013). 
$\mathrm{Na}$ cartela central do frontal do altar está a mensagem Florete Flores. A referida inscrição está presente em Eclesiástico (39: 19) da seguinte forma: "Florete flores quasi lilium date odorem et frondete in gratian et conlaudate canticum et benedicite Dominum in operibus suis". Sua tradução, proveniente da Vulgata, ${ }^{8}$ é: "Dai flores como o lírio, exalai perfume e estendei graciosa folhagem. Cantai cânticos e bendizei o Senhor nas suas obras".

$\mathrm{Na}$ Bíblia, em Eclesiástico (39: 13-15), esse entendimento pode ser ainda amplificado:

Escutem-me, filhos santos, e cresçam como roseira plantada à beira da água corrente. Espalhem bom perfume como incenso e floresçam como lírio. Espalhem perfume e entoem um canto, bendizendo ao Senhor por todas as suas obras. Engrandeçam o nome do Senhor e proclamem os louvores dele com seus cânticos e cítaras.

A metáfora de espalhar o bom perfume e florescer como o lírio é ampla e trataremos da sua interpretação no decorrer deste texto, estabelecendo os possíveis diálogos e conexões.

No frontal do altar, estão presentes motivos fitomorfos, como o lírio, rosa, açucena, angélica, girassol, verbasco e jasmim, que bem traduzem as citações em Eclesiástico e dialogam diretamente com a missão do Seminário de Nossa Senhora de Belém. A simetria está presente em todo o painel. As folhas de acanto circundam a obra e se entrelaçam junto às flores. A pomba, o beija-flor, o sabiá, a crisálida e a borboleta também integram o conjunto e complementam o cenário poético e iconográfico.

A leitura de Eclesiástico diante do frontal do altar nos faz reconhecer ali a Palavra, a Sagrada Escritura, na sua ilustrada amplitude. Entretanto, as referências simbólicas dos motivos zoofitomorfos são fundamentais à sua interpretação e iniciamos esse repertório com alguns dos exemplares.

Observamos, inicialmente, a borboleta e a crisálida, uma conhecida representação simbólica. Valéria Cruz (2001, p. 70), em A simbólica dos animais: bestiário e outros textos, afirma que a borboleta, mediante a metamorfose, a transmutação, está associada à Ressurreição: "por causa de sua vida curta, e de sua transformação de lagarta em borboleta, esteve vinculada aos ciclos de vida-morte-renascimento, representando tanto a imortalidade da alma e do eterno, como a futilidade e a transitoriedade de tudo que existe".

8 Chama-se Vulgata a tradução da Bíblia grega para o latim, feita por São Jerônimo, no século V. Sua denominação foi consolidada em 1546, após o Concílio de Trento, que estabeleceu um texto único e a confirmou como a Bíblia oficial da Igreja. 
A transitoriedade e efemeridade da vida foram amplamente utilizadas na iconografia cristã, que se apropriou de diversos elementos simbólicos na sua representação.

Louis Charbonneau-Lassay (1991), em Bestiary of Crbist, ${ }^{9}$ estabelece também uma relação entre a lagarta e a borboleta como símbolo da Ressurreição de Cristo:

Todos os vermes, destinados a sofrer uma metamorfose, são os seus emblemas, mas a transformação da lagarta, mais do que de qualquer outra larva, figura em simbolismo cristão como a representação do corpo quebrado de Jesus que se transformou no corpo glorioso que emergiu da escuridão do túmulo. No século V, um decreto pontifício do Papa Gelásio I declarou que Cristo era um verme, não porque ele foi humilhado, e se humilhou, mas porque ele ressuscitou: 'Verme que ressucitou'. (CHARBONNEAU-LASSAY, 1991, p. 346, tradução nossa $)^{10}$

A representação da borboleta e crisálida, no frontal do altar, sugere, da mesma forma, os estágios do homem, as etapas da vida. Charbonneau-Lassay (1991) complementa sua interpretação com a crisálida recém-saída do casulo, um estágio intermediário entre a lagarta e a borboleta:

Tudo isso ainda está enrugado e encolhido, as asas coladas ao corpo indeterminado, pois a ex-lagarta tornou-se o que é ainda apenas a crisálida, até o primeiro vôo, sob o calor dos raios do sol ao ar livre, faz-se borboleta. Foi por ponderar os mistérios do casulo que antepassados estabeleceram as analogias que fizeram da lagarta um símbolo de Cristo. (CHARBONNEAU-LASSAY, 1991, p. 346, tradução nossa $)^{11}$

A metamorfose da borboleta traz, nesse antigo, simbolismo dos estágios de vida, morte, transformação ou de ressurreição. O casulo, estágio intermediário entre a lagarta, crisálida e a borboleta, pode ser entendido como o período entre o descimento de Jesus da cruz e a sua ressurreição. Dessa forma, pelo simbolismo zoomorfo, está representada a Ressurreição de Cristo no frontal do altar.

9 O Bestiário de Cristo.

10 "All worms, destined to undergo a metamorphosis, are his emblems, but the transformation of the caterpillar, more than of any other larva, figures in Christian symbolism as the representation of the broken body of Jesus transformed into the glorious body which emerged from the darkness of the tomb. The fifth century pontifical decree of Pope Gelasius I declared that Christ was a worm, not because he has humbled, and humbled himself, but because he has resurrect: 'Vermis quia resurrexit."

11 "All this is still wrinkled and shrunken, the wings stuck to the body and indeterminate; for the former caterpillar has become what is as yet only the chrysalis, until the first flight, under the warmth of the sun's rays in the free air, makes into the butterfly. It was by pondering the mysteries of the cocoon thatforefathers established the analogies which have made the caterpillar a symbol of Christ". 


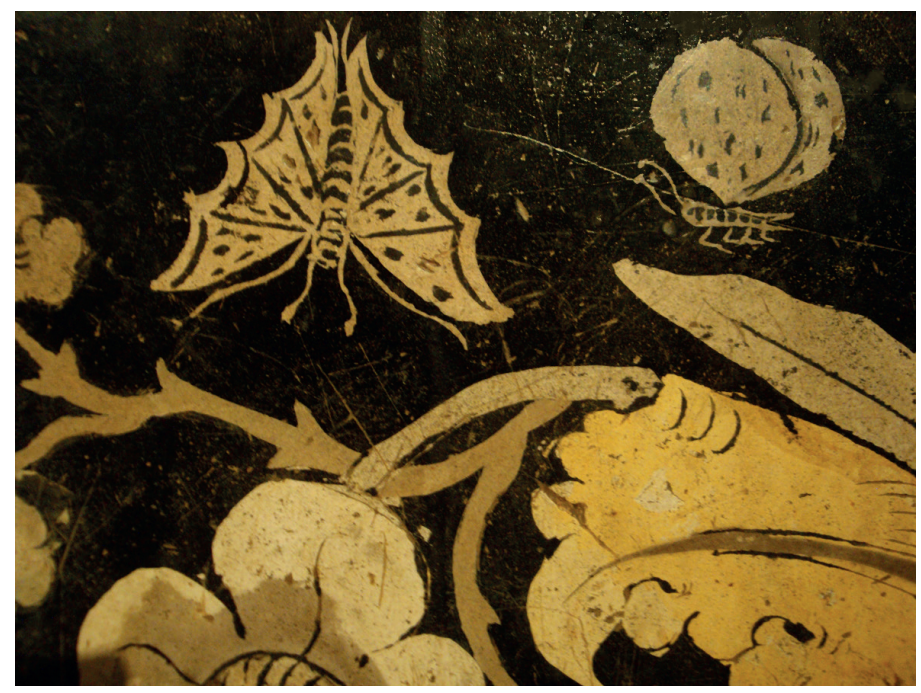

Figura 4 - Detalhe de borboleta e crisálida no frontal do altar Fonte: Neves (2013).

No frontal, também observamos pássaros entremeados às flores e folhas de acanto. Para George Ferguson, em Signs \& symbols in Christian art, ${ }^{12}$ os pássaros são o símbolo da alma, e este simbolismo remete à arte na Antiguidade, no Egito. Esclarece o autor que, no Cristianismo, "este simbolismo pode estar implícito em pinturas do Menino Jesus segurando um pássaro em Sua mão ou segurando um amarrado a uma corda. São Francisco de Assis é frequentemente representado pregando para os pássaros". (FERGUSON, 1961, p. 13, tradução nossa) $)^{13}$

A pomba (Columba livia) é a primeira ave e apresenta-se junto à cartela central à base do painel. São muitas as referências dessa ave na Sagrada Escritura e podemos iniciar com a sua disciplina e obediência a Noé, quando a solta diante das águas (Gêneses 8, 6-12). Seu simbolismo esteve relacionado à pureza e à paz. Segundo Ferguson (1961), a representação mais importante da pomba está no simbolismo do Espírito Santo, que aparece na Anunciação de Maria, no Batismo de Jesus Cristo e na representação da Santíssima Trindade. A ave também é um atributo de alguns santos e apresenta-se em várias situações no Cristianismo, desde os seus primórdios.

12 Signos \& símbolos da arte cristã.

13 "This symbolism may be implied in the pictures of the Christian Child holding a BIRD in His hand or holding one tied to a string. St. Francis of Assis is often represented preaching to the birds." 


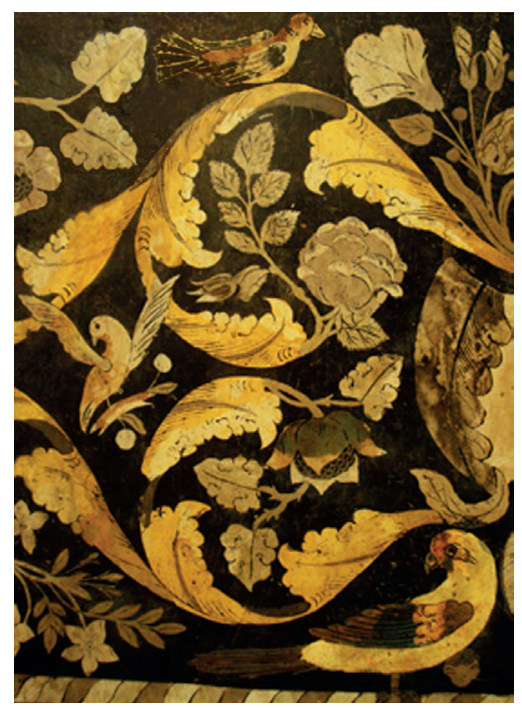

Figura 5 - A pomba, o beija-flor e o sabiá no frontal Fonte: Neves (2013).

Entre os pássaros, também está o beija-flor, ave da família Trochilidae, ${ }^{14}$ que, apesar de não apresentar o avantajado e característico bico no referido desenho do painel, pode ser facilmente identificado pelo seu formato e posicionamento das asas. Também chamado colibri, esse pássaro alimentou a cronística colonial pelas características fantásticas que lhe foram atribuídas. Os padres da Companhia de Jesus, assim como os colonos do Brasil, acreditavam no seu potencial de metamorfose a partir da borboleta. Essa referência pode ser entendida mediante o texto do jesuíta Fernão Cardim (1548?-1625), Tratados da Terra e gente do Brasil, escrito entre 1583 e 1601, no momento em que descreve o beija-flor:

O corpo he pardo, tem o bico muito comprido, e a lingoa de dous comprimentos do bico; são muito ligeiros no voar, e quando voão fazem hum estrondo como abelhas, e mais parecem abelhas na ligeireza que pássaros, porque sempre comem de vôo sem pousar na arvore; assi como abelhas andão chupando o mel das flores; têm dous princípios de sua geração: huns se gerão de ovos como outros pássaros, outros de borboletas, e he cousa para ver, huma borboleta começar-se a converter neste passarinho, porque juntamente he borboleta e pássaro, e assi se vae convertendo até ficar neste formosíssimo passarinho; cousa maravilhosa, e

14 O pássaro é originário das Américas e possui 108 gêneros e 322 espécies. 
ignota aos philosophos, pois hum vivente sem corrupção se converte noutro. (CARDIM, 1925, p. 53)

Observamos, no texto do Padre Cardim (1925), a referência à borboleta como um ser "sem corrupção", uma característica virtuosa transferida e conferida, simbólica e metaforicamente, ao beija-flor. Entretanto, vale salientar que a observação no texto do Padre Fernão Cardim não foi pontual, única. A metamorfose da borboleta em beija-flor acabou se solidificando no imaginário colonial, principalmente entre os religiosos da Companhia de Jesus.

Afirma Sérgio Buarque de Holanda (2000), em Visão do paraíso, que a informação foi reproduzida nos textos dos jesuítas Simão de Vasconcelos e João de Almeida, como também pelo médico e naturalista holandês Guilherme Piso (1611-1678), ${ }^{15}$ que, "bem longe de se mostrar duvidoso quanto à realidade de tão extraordinária mudança, cuida não só de aboná-la como de ilustrá-la com novas minúcias". (HOLANDA, 2000, p. 262)

No caso dos jesuítas, estes não somente relatam a metamorfose, mas demonstram tê-la testemunhado. Padre Fernão Cardim refere-se ao beija-flor como Guainumbig, Guaracigá e Guaracigaba, nomes indígenas na região das Américas, e complementa que "nas Antilhas lhe chamão o pássaro resuscitado, e dizem que seis mezes dorme e seis mezes vive". (CARDIM, 1925, p. 52)

A metamorfose da borboleta, assim como a do beija-flor, também pode ser entendida em outro patamar. Tratando-se, neste caso, do Seminário de Belém, e associando a educação e doutrina religiosa como instrumento de transformação/ metamorfose do gentio, esta se dá de uma forma quase alquímica na transmutação do chumbo (ignorância) no ouro (conhecimento).

A identificação do terceiro pássaro não foi possível com precisão, a partir do desenho, mas a semelhança com as diversas espécies de sabiás ${ }^{16}$ nos remete à grande possibilidade de que este pássaro esteja ali representado. Embora essas espécies possuam pernas mais longas que as apresentadas no desenho do frontal do altar, a semelhança com o sabiá do campo (Mimus saturninus) é grande. Este é conhecido pela amplitude de seu repertório musical, inclusive, por imitar o canto de outras seis aves.

É possível que na metáfora de "espalhar o bom perfume", amplificada pelo canto e pelas palavras do Evangelho, teria aquele pássaro, simbolicamente, essa

15 Guilherme Piso escreve, em 1648, a Historia Naturalis Brasiliae (História natural do Brasil), o primeiro livro naturalista escrito sobre o Brasil. A publicação conta com as observações do alemão George Marcgrav, que também esteve no Brasil e registrou, com seus desenhos e pinturas, a flora e a fauna locais.

16 Sabiá laranjeira (Turdus rufiventris); Sabiá barranco (Turdus leucomelas); Sabiá poca (Turdus amaurocbalinus; Sabiá do campo (Mimus saturninus); e Sabiá-da praia (Mimus gilvos). 
virtude e função diante da sua representação na obra. Mas são as flores que possuem, primeiramente, a função do "exalar o bom perfume".

Luís Alberto Casimiro (2009, p. 152), em Iconografia da anunciação: símbolos e atributos, afirma que "também o Cristianismo, desde os seus primórdios, dando continuidade à tradição do povo bíblico, faz uso das flores para dar expressão a novos conceitos relacionados com as suas crenças". Complementa, ainda, o autor, que "se percebe a força do simbolismo do mundo vegetal que vai atribuindo, a símbolos antigos, novos significados ou criando outros que vão perdurando ou desaparecendo ao longo dos séculos”. (CASIMIRO, 2009, p. 153)

A rosa (Rosa spp) e o lírio (Lilium sp) são significativos no simbolismo cristão como sinalizamos em Eclesiástico. Para Gerd Heinz-Mohr, em Dicionário de símbolos: imagens e sinais da arte cristã, "a rosa, por sua cor preponderantemente vermelha, símbolo antiquíssimo do amor, aludindo, ou à taça, que apanha o sangue de Cristo, ou às chagas do próprio Cristo. [...] Com isso, se alude também à rosa mística da ladainha de Nossa Senhora”. (HEINZ-MOHR, 1994, p. 312)

Frei Isidoro de Barreira interpreta de outra forma, em Tractado das significacoens das plantas, flores e fructos que se referem na Sagrada Escriptura:

O nome de rosa por significar graça, convém propriamente a Virgem Raynha dos Anjos, \& Senhora nossa, que foi toda cheia de graça, \& por isso Rosa, que se entre as flores tem o primeiro lugar, esta Senhora o tem eminentíssimo entre todas as mulheres, flor de todas as flores, \& de todas as Virgens. (BARREIRA, 1622, p. 381)

As rosas vermelhas, quando com espinhos, aludem à coroa de Cristo, instrumento da Paixão. O lírio, por sua vez, esteve associado à pureza, inocência e virgindade. Desta forma, foi, por muitas vezes, considerada a flor de Maria, de Nossa Senhora, mas também uma flor que representou os mártires. Entretanto, a iconografia refere-se à flor da Virgem Maria como a açucena.

Luis Alberto Casimiro (2009, p. 153) esclarece que, "apesar de serem, muitas vezes, utilizados como sinónimos, é necessário referir que a açucena e o lírio são flores diferentes. No caso das pinturas portuguesas da Anunciação, apenas são representadas açucenas". O autor continua:

A presença desta flor pode ser entendida, não só, como uma alusão à Primavera, tempo privilegiado de flores, dado que no calendário juliano, tinha início no dia 25 de Março, dia em que ocorreu a Anunciação, como ainda ao nome de Nazaré (que para S. Bernardo significa "flor"), mas sobretudo, diz respeito à própria Virgem Maria para indicar que Cristo nascerá de uma Virgem. Por isso, são raras as pinturas em que falta a açucena, seja numa jarra ou nas 
mãos do Anjo Gabriel, como símbolo da eleição de Maria, de pureza, inocência, virgindade e castidade. (CASIMIRO, 2009, p. 153)

No frontal do altar de Belém de Cachoeira estão as duas flores: lírio e açucena. Convém ressaltar que muitas flores que "exalam o bom perfume" são consideradas símbolos marianos, isto é, associadas à Virgem Maria. É o caso da angélica, jasmim, verbasco e algumas outras espécies. Da mesma forma, o simbolismo do lírio é tratado em várias citações na Sagrada Escritura, que, por sua vez, acompanha variadas linhas de interpretação entre os autores.

Para Gerd Heinz-Mohr (1994), o lírio é "na tradição bíblica, símbolo da eleição, da escolha do ser amado. Assim, Israel se viu escolhido dentre todos os povos e Maria dentre todas as mulheres de Israel". Complementa o autor dizendo que "pode-se ler na figura do lírio a entrega confiante à vontade de Deus que vela pelos seus eleitos, a entrega mística à divina graça”. (HEINZ-MOHR, 1994, p. 222)

Por sua vez, Frei Isidoro de Barreira (1622, p. 387), ao relatar o significado simbólico do lírio, esclarece que "Sam Hieronimo diz que, quando Deos nos alumia, \& das trevas do pecado traz a pureza, \& luz da graça, entam florescemos como o lírio". O simbolismo das flores e plantas é amplo e não se esgota neste texto. O mesmo ocorre com a metáfora de "espalhar o bom perfume".

Embora o frontal do altar se refira diretamente a Eclesiástico, Padre Alexandre de Gusmão, na obra Escola de Belém, Jesus Nascido no Presépio, esclarece, didaticamente, o ato de florescer como o lírio, em "Isaías":

O Propheta Isaías, falando da vinda do Messias, diz que hade então florecer a Fé como o lírio, \& produzir como as árvores a sua rama: florebit quase lilium \& germinans germinabit laetabunda, ${ }^{17}$ porque sendo antes a Igreja dos Fieis, que era a Synagoga, como hum deserto seco sem folha, \& sem flor; com o Nascimento de Christo se formou um jardim de flores, \& boninas. Para confirmação disto, na noite em que o Menino nasceo, o Ceo, \& a terra florecerão; a terra porque os prados se povoarão de flores; o Ceo, porque as nuvens se orvalharão de flores, porque onde a Vulgata lê Roraste caeli desuper, ${ }^{18}$ treslada o siríaco ${ }^{19}$ Florete, florecei; senão hé, que vendo o Ceo agora a terra convertida em Ceo estrellado, quer com isso converterse em terra florecente; ou por-

17 Isaias 35, 1-2: Florebit quase lilium \& germinans germinabit et exultabit laetabunda (E o exultará e florescerá como o lírio florescerá abundantemente).

18 Isaías 45, 8: Rorate coeli desuper et nubes pluant justum (Destilai, ó céus, dessas alturas, e as nuvens chovam justiça).

19 Dialeto do aramaico que foi a principal linguagem do cristianismo oriental, assim como os livros do judaísmo e cristianismo. Aprendia-se o siríaco no Seminário de Belém de Cachoeira. 
que vendo mais bela a terra só com essa flor nascida, quer converter em flores suas estrellas o Ceo. (GUSMAO, 1678, p. 179-180, grifo do autor)

Como já dissemos, a metáfora é ampla e pode ser interpretada por diversos caminhos. Pelo autor, o jardim de flores se forma a partir do nascimento de Jesus, que cresce e amplifica o rebanho dos Céus na terra.

Em outra obra, $A$ arte de criar bem os filhos na idade da puerícia, Padre Alexandre de Gusmão (2004, p. 41) exemplifica que "os meninos são as flores, são também a esperança da república".

Como síntese iconológica, na propagação da fé cristã, os vícios são vencidos pelas virtudes, na profusão das flores e seus perfumes, abençoados pelas mãos e vontade divinas. Assim foi representada no frontal do altar-mor da Igreja do Seminário de Belém de Cachoeira.

\section{Ut pictura poesis}

A relação entre pintura e poesia é antiga e permeou os textos clássicos da Antiguidade. A expressão ut pictura poesis, que significa "pintura é poesia", ficou conhecida a partir da interpretação da Ars Poetica, ${ }^{20}$ de Horácio $^{21}$ (65 a. C. - 8 a. C.).

$\mathrm{O}$ conceito influenciou o pensamento estético na modernidade, permitindo o diálogo e interação entre texto e imagem, ou poesia e pintura, forma como ficou mais conhecido.

A relação entre pintura e poesia pode ser entendida no Seminário de Nossa Senhora de Belém de duas formas, em dois patamares.

O primeiro patamar, na relação direta entre o frontal do altar e Eclesiástico, quando dialogam poeticamente, a ornamentação com a Sagrada Escritura. Ao procedermos à leitura de Eclesiástico (39: 19), diante do frontal, observamos que a obra supera a condição de ornamento e interage com o texto, "criando vida". Da mesma forma, o texto de Eclesiástico ganha outras proporções diante da obra. Assim, nessa simbiose, se complementam e agregam valores um ao outro.

No segundo patamar, está a obra literária do Padre Alexandre de Gusmão, em diálogo com a sua obra artístico-pedagógica: o Seminário de Belém de Cachoeira. Para melhor entendimento desse segundo patamar, faz-se necessário conhecer um pouco de seus escritos.

Dez anos anteriores à fundação do Seminário de Belém de Cachoeira, escrevia o Padre Alexandre de Gusmão a obra Escola de Belém, Jesus Nascido no Presépio. Era o ano de 1676, e o referido padre tinha o cargo de Mestre de Noviços no Colégio da Bahia. Publicada em Évora, em 1678, a obra norteia o que seria, mais

20 Arte Poética.

21 Quinto Horacio Flaco. 
tarde, praticado no Seminário. No Livro I, Da origem \& fundação da escola de Bethlem, escreve, Gusmão (1678, p. 2):

A aula Real onde collocou a cadeira Magistral, hé a lapa onde nasceo, que hé hua cova que a natureza fez ao pé de um rochedo, junto a Bethlem, aberta por todas as partes, para ser freqüentada de todos. A cadeira, hé a manjedoura onde a Virgem sua may o reclinou; as insígnias doutorais, são as faixas em que o envolveo; as tapeçarias, são as teas das aranhas; as alcatifas, a terra nua; o guarda, hé o santo Joseph; o Bedel que dá recado aos estudantes, hé o anjo que deu aviso aos santos Pastores; o sino, hé o Celeste que chamou aos sábios do Oriente

P. Alexandre de Gusmão (1678) associa, de forma pedagógica, o ambiente escolar ao ambiente da manjedoura no nascimento de Jesus. A poética da Sagrada Escritura, associada ao ambiente escolar, está presente em toda a publicação. Após a leitura, foi possível compreender a sua visão idealizadora na fundação daquele Seminário e a possibilidade de influência da obra no nome Seminário de Nossa Senhora de Belém. Mais adiante, no Livro IX, Do papel, penna \& tinta da Escola de Bethlem:

E conforme essa vontade do Senhor, os nossos corações hão de ser o papel, de que hão de usar os discípulos da Escola de Bethlem, fazendo das teas, ou membranas do coração, os quadernos em que tome a postilla, que no coração nos dita este divino Mestre. (GUSMÃO, 1678, p. 43)

O que Padre Gusmão escreveu tornou-se realidade. Idealizou na literatura e realizou artística e pedagogicamente. Posteriormente, em 1685, prestes a fundar o Seminário, escreve $A$ arte de criar bem os filhos na idade da puerícia. Na obra, estabelece novamente as associações simbólicas e metafóricas. Ao citar que São Jerônimo via nos filhos de uma família "as flores de um jardim”, interpreta que:

Por essa metáfora de flores, digo, que assim como o jardim, para que suas flores venham a servir de agrado à vista, de ornato dos altares, e de coroas para a cabeça, é necessária toda a vigilância, toda a indústria, todo asseio, curiosidade e aplicação do jardineiro; assim para que os filhos venham a ser a alegria dos pais, ornato dos altares de Deus, coroa e glória de suas famílias, é necessária toda a vigilância, indústria e aplicação dos pais na idade dos meninos. (GUSMÃO, 2004, p. 19)

Padre Gusmão ressalta, em toda a sua obra, a importância da família na criação, a vigilância, a obediência dos filhos e, da mesma forma, as virtudes e 
as bênçãos divinas conferidas à família. Ressaltamos que no Inventário daquele Seminário constavam altares colaterais da Senhora Sant'Ana e do Senhor São Joaquim, pais da Virgem Maria.

Assim, três obras podem ser interpretadas como fundamentais no propósito ideológico e artístico do Seminário de Nossa Senhora de Belém: Escola de Belém, Jesus Nascido no Presépio, dedicada a São José; $A$ arte de criar bem os filhos na idade da puerícia, dedicada ao Menino Jesus; Rosa de Nazareth nas montanhas de Hebron. Virgem Nossa Senhora na Companbia de Jesus, de 1709, dedicada à Virgem Maria.

É possível que a trilogia que compõe a Sagrada Família norteie o pensamento do Padre Alexandre de Gusmão para o Seminário e também para o programa iconográfico ali estabelecido.

Na segunda obra, a que fizemos referência, Padre Gusmão estreita a relação metafórica e simbólica entre a arte e a formação religiosa:

Um político disse que eram os ânimos dos meninos como uma tábua rasa que um insigne pintor tem aparelhada para pintar nela qualquer imagem, o que nela quiser pintar isto representará, se anjo, anjo; se demônio, demônio representará. E assim, como sair bem ou mal pintado, o quadro depende das primeiras linhas que nele o pintor lançou; assim o sair bem, ou mal criado, o filho depende dos primeiros ditames que nele, como tábua rasa, debuxou o pai enquanto menino. (GUSMÃO, 2004, p. 13-14)

Sabiam os jesuítas da eficácia na formação religiosa do público infantil, e assim o fizeram na conversão dos pequenos índios, nas escolas estabelecidas nas aldeias. Espalharam, desta forma, o "bom perfume".

No Seminário de Nossa Senhora de Belém, Padre Alexandre de Gusmão foi o grande interlocutor entre a poesia e a pintura, entre o texto e a imagem, entre o ideal e o concreto, utilizando-se desse conceito em toda a sua amplitude. Escreveu, edificou, esculpiu, ensinou, pregou, convenceu, converteu. Esse foi o seu legado: Florete Flores quasi lilium.

\section{Considerações finais}

No templo religioso do Seminário, eram realizadas as práticas litúrgicas diárias dos religiosos da Companhia, dos meninos internos, além da missa dominical para a comunidade local, cultivando os princípios religiosos e solidificando a doutrina católica de forma contínua e pedagógica, formando, assim, o seu rebanho.

Embora não conheçamos o real programa iconográfico ali estabelecido, mas interpretando a Igreja como um local repleto de signos e símbolos, é possível que aquele conjunto ornamental tenha se desenvolvido em contínuo diálogo 
entre os conceitos e metáforas da Sagrada Escritura e doutrina cristã, e a sua ampla interpretação artística como um exercício do desenvolvimento intelectual e religioso, instrumento de erudição e aperfeiçoamento presente no universo da Companhia de Jesus.

É no templo, na Igreja, que conceitualmente se reúne a comunidade em nome de Jesus Cristo e, assim, cultua-se seu nome e celebra-se a prática religiosa. O altar, espaço destinado à Palavra, à Eucaristia, ao sacerdote, é dotado de ampla carga simbólica primordial, pois ali estão os paramentos litúrgicos fundamentais à realização do culto e à atenção dos fiéis.

Desta forma, assume o frontal do altar a sua real importância diante do rebanho que partilha o templo, ilustrando e ecoando a Sagrada Escritura, quase como um escudo e, neste caso específico, aborda o princípio e a legenda do Seminário de Belém de Cachoeira: Florete Flores.

O Seminário de Belém de Cachoeira ainda representa um tema lacunar no seu repertório iconográfico. Entretanto, reconhecemos que muitos de seus conceitos estão presentes na obra literária do Padre Alexandre de Gusmão, seu idealizador e fundador. Desta forma, consideramos fundamental o acesso à sua obra literária, juntamente com a pesquisa iconográfica, como auxílio no esclarecimento de algumas questões que possam surgir nos processos de investigação.

\section{Referências}

BARREIRA, I. de. Tractado das significacoens das plantas, flores e fructos que se referem na sagrada escriptura. Lisboa: Pedro Craesbeeck, 1622.

CARDIM, F. Tratados da terra e gente do Brasil. Rio de Janeiro: J. Leite \& Cia, 1925.

CASIMIRO, L. A. E. Iconografia da Anunciação: símbolos e atributos. Revista da Faculdade de Letras: Ciências e Técnicas de Patrimônio. Porto, v. 7-8, p. 151-174, 2009.

CHARBONNEUA-LASSAY, L. The bestiary of Christ. New York: Arkana: Parabola Books, 1991.

CRUZ, V. A. A simbólica dos animais: volume 1: bestiário e outros textos. São Paulo: Fiuza, 2001.

ECLESIASTICO. In: Biblia Sagrada: edição pastoral. São Paulo: Paulus, 1990. p. 934.

FERGUSON, G. Signs \& symbols in christian art. London: Oxford University, 1961.

GODOFREDO FILHO. O Seminário de Belém de Cachoeira. Revista do Patrimônio Histórico e Artístico Nacional, Rio de Janeiro, n. 1, p.101-111, 1937.

GOMBRICH, E. H. O sentido de ordem: um estudo sobre a psicologia da arte decorativa. Tradução de Daniela Pinheiro Machado Kern. Porto Alegre: Bookman, 2012.

GOMES JUNIOR, G. S. Palavra pelegrina: o barroco e o pensamento sobre artes e letras no Brasil. São Paulo: Edusp, 1998. 
GUSMÃO, A. de. A arte de criar bem os filhos na idade da puerícia. São Paulo: Martins Fontes, 2004.

GUSMÃO, A. Escola de Belém, Jesus Nascido no Presépio. Évora: Oficina da Universidade de Évora, 1678.

HANSEN, J. A. Ratio Studiorum e política católica ibérica no século XVII. In: VIDAL, D. G.; HILSDORF, M. L. S. (Org.). Brasil 500: tópicas em história da educação. São Paulo: Edusp, 2001. p. 13-41.

HEINZ-MOHR, G. Dicionário de símbolos: imagens e sinais da arte cristã. São Paulo: Paulus, 1994.

HOLANDA, S. B. Visão do paraíso: os motivos edênicos no descobrimento e colonização do Brasil. São Paulo: Brasiliense: Publifolha, 2000.

IPHAN. Igreja do Seminário de Belém (Cachoeira, BA). [S.1.], [200-]. Disponível em: <www. iphan.gov.br/ans.net/tema_consulta.asp?Linha $=$ tc_belas.gif\&Cod=1032>. Acesso em: 22 nov. 2013

LEITE, S. Artes e Ofícios dos Jesuitas no Brasil. Natal: Sebo Vermelho, 2008.

LEITE, S. Breve bistória da Companbia de Jesus no Brasil 1549-1760. Braga: Livraria A.I., 1965.

NEVES, B. Frontal do altar da Igreja do Seminário de Nossa Senhora de Belém, Cachoeira, Bahia. 2013. 1 Album (5 fot.): color. 10x15cm.

OT'T, C. História das artes plásticas da Babia (1550-1900). Salvador: Alfa Gráfica: Editora Limitada, 1993.

PEIXOTO, A. Livro de horas. Rio de Janeiro: Agir, 1947.

SERRÃO, V. Os programas imagéticos na arte barroca portuguesa e a sua repercussão nos Espaços Coloniais Luso-Brasileiros. In: CONGRESSO INTERNACIONAL DO BARroCO IBERO-AMERICANO, 4., 2006, Ouro Preto. Atas... Ouro Preto: 2006. p. $1389-1412$. 